\title{
Selected Reference Books of 1983-84
}

\section{Eugene P. Sheehy}

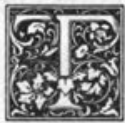

his article continues the semiannual series originally edited by the late Constance M. Winchell. Although it appears under a byline, the list is a project of the reference departments of Columbia University's Butler and Lehman libraries, and notes are signed with the initials of the individual staff members. ${ }^{1}$

Since the purpose of the list is to present a selection of recent scholarly and general works of interest to reference workers in university libraries, it does not pretend to be either well balanced or comprehensive. A brief roundup of new editions of standard words, continuations, and supplements is presented at the end of the article. Code numbers (such as AE213, CJ34) have been used to refer to titles in the Guide to Reference Books and its supplements. ${ }^{2}$

\section{BIBLIOGRAPHY}

Conlon, Pierre M. Le siècle des lumières: bibliographie chronologique. Genève, Droz, 1983- . v.1- . (In progress) (Histoire des idées et critique littéraire, v.213) LC 83-232638.

Contents: v.1, 1716-1722. 75SwF.

This bibliography lists the first editions of works written by eighteenth-century authors published in France in any language and French writings of the period which were published outside France. The chronological list of works will even- tually cover the period $1716-89$ and will help fill a gap in eighteenth-century French national bibliography. All subject fields are included except administrative and legal documents, these having already been sufficiently covered by the Catalogue général des actes royaux (1910-60) and the Catalogue des factums (1890-1936), both published by the Bibliothèque Nationale, Paris. Conlon has drawn bibliographic data from published library catalogs such as those of the Bibliothèque Nationale and the British Museum, the National Union Catalog, and other sources such as the Cataloge de l'Histoire de France (1855-95; Guide DC83), and lists of theses. Items which were examined by the editor are marked with an asterisk.

Each bibliographic entry comprises author (if known), title, publisher, date and place of publication, format, and pagination. Each entry is followed by as many as five library locations with call numbers. This, therefore, serves as a union catalog of eighteenth-century French publications (in both linguistic and geographic senses of the term). Entries are arranged by year, then alphabetically by author or title. Locations listed are mainly within France, but they include libraries in Belgium, Switzerland, Italy, Holland, Great Britain, and the United States (i.e., references to NUC). A tremendous variety of material is included, ranging from a leaflet of two pages to multivolume sets, and covering polemical writings, religious and medical

1. Mary Cargill, Anita Lowry, Eileen Mcllvaine, Louise Sherby, Sarah Spurgin, Junko Stuveras; Lehman Library: Laura Binkowski, Diane Goon, Debi Hassig.

2. Eugene P. Sheehy, Guide to Reference Books, 9th ed. (Chicago: American Library Assn., 1976); Supplement (Chicago: American Library Assn., 1980); Second Supplement (Chicago: American Library Assn., 1982). 
treatises, funeral orations, technical and trade publications, as well as works of history and literature. Indexes by author and title and a cumulative index for the completed set are promised.-J.S.

Gorman, G. E. and Mahoney, M. M. Guide to Current National Bibliographies in the Third World. München, H. Zell/K. G. Saur, 1983. 328p. \$37. ISBN 0-90545008-6.

The onerous task of maintaining a collection of current national bibliographies should be considerably lightened by this compilation, which will be welcomed by reference librarians, collection development librarians, and research workers. It provides a kind of state-of-the-art report for Third World bibliographic control at the national level, listing "some eighty national bibliographies, complementary compilations or substitute services for sixty developing countries plus ten regional bibliographies for six regions." Introd. Arranged by region and individual country, it includes only those national bibliographies known to have published at least one volume or issue since 1975 or which began publication by mid-1983. For each country is given a bibliographical citation to the national bibliography (or effective substitute), notes on the history, scope, and content thereof, and an analysis or critique of the publication and its general usefulness. There is a title index. Not only will the Guide serve as an aid to identifying new national bibliographies, but the history notes (with their indications of publication patterns and periods of suspension) will be invaluable for ascertaining the completeness of a given library's existing files.-E.S.

Nineteenth Century Short Title Catalogue. Series I, Phase I, 1801-1815. [Newcastle-upon-Tyne, Eng.], Avero, [1984]- . v.1- . (In progress) $\$ 1495$ the set. ISBN 0-907977-10-3.

Contents: v.1, A-C.

Under the chairmanship of John W. Jolliffe of the Bodleian Library, the Nineteenth Century Short Title Catalogue Project "aims to provide increasingly complete listings of British books printed between 1801 and 1918 in order of au- thors, subjects, places of imprint, titles, and dates of publication. British books are taken to include all books published in Britain, its colonies and the United States of America; all books in English wherever published; and all translations from English."-Introd. The project is being completed in two phases. Phase I will produce three multivolume series, 1801-1815, 1816-1870, and 1871-1918, of entries extracted from the published and unpublished catalogs of the Bodleian Library, the British Library, the Library of Trinity College, Dublin, the National Library of Scotland, and the University Libraries of Cambridge and Newcastle. Phase II will produce supplementary series from the catalogs of specialist libraries.

Entries in the catalog follow the form and order of those in the British Museum's General Catalogue, with crossreferences at alternative headings. Each entry has four parts: a reference number, an author statement, a short title followed by subject classification numbers, and an edition statement which includes place of imprint (but not printer or publisher), bibliographic notes, and library location symbols. Each volume contains an imprintplace index subdivided by year, and a subject index. As each series is completed the final volume will contain cumulated subject and imprint indexes, and there will be an alphabetical list of the complete titles on microfiche.

The Nineteenth Century Short Title Catalogue will become more and more useful as the project continues. There are many flaws - there is no index of publishers or printers, subject indexing varies in depth, the National Union Catalog is not among the source catalogs, and the actual books have only rarely been examined. Still, the work will be very useful to scholars since it provides the first comprehensive list of nineteenth-century English books.-S.S.

\section{MANUSCRIPTS}

British Library. Department of Manuscripts. Index of Manuscripts in the British Library. Cambridge, Eng., ChadwyckHealey, 1984- .v.1- . (In progress) $\$ 1,800$ the set. LC $84-673510$. ISBN 085964-140-6.

Contents: v.1, A-Borron. 
In preparation since 1963, this important work (which is to be complete in eleven volumes) serves as a comprehensive name and place index to the collections of the Department of Manuscripts of the British Library. All the collections acquired prior to 1950 are covered, ranging, as the publisher's announcement notes, "from early seals and charters to the records of twentieth-century institutions and the papers and correspondence of modern writers, artists and politicians." The Index reproduces in a single alphabet more than one million entries for personal and place names appearing in over thirty catalogs and indexes, both published and unpublished. Extensive editorial work was required in order to bring together variant forms of names, to establish preferred forms, etc., and there are numerous crossreferences. Each entry includes the name of the item, the name of the collection to which it belongs, its number within the collection, and its folio or article number; these numbers can be used for ordering photocopies or microfilm. The prefatory matter provides useful explanatory information about the compilation, coverage, and use of the Index.-A.L.

\section{MICROFORMS}

Dodson, Suzanne Cates. Microform Research Collections: A Guide. 2nd ed. Westport, Conn., Meckler Pub., [1984]. 670p. (Meckler publishing series in library micrographics management, 9) \$125. LC 83-22117. ISBN 0-930466-66-7.

Dodson is to be commended for providing a new edition of her useful guide so promptly and for maintaining the reliability of the information included. Coverage has been expanded from 200 microform collections in the 1978 volume (Suppl. AA29) to about 375 in this edition-which is quite a jump in only six years, and says something about the growth of micropublishing. The guide is still selective, covering those collections which are considered useful, likely to be owned, large, timely, and reviewed. A typical entry again includes title, publisher, format, price, citations to reviews, arrangement and bibliographical control, references to bibliographies and indexes, notes on scope and content, and date of publication (or date when publication began). This edition adds size of collection (number of physical items and number of titles) and publishing status (in process, continuing series, etc.), and the prices are now dated.

In view of her long experience with frequent changes of title for microform sets, Dodson offers an amusing and heartfelt plea to micropublishers to select a title and stay with it, but she has devised a numbering scheme for the entries which allows both for changes of title and insertion of new titles in future editions. The problem of variant titles is dealt with in the index by including "every variation on a title which I could find or invent." -Pref. Subject entries for collections as a whole have been added in the new index.-E.M.

\section{RELIGION}

The Penguin Dictionary of Religions. Ed. by John R. Hinnells. [London], Allen Lane, [1984]. 550p. il., maps. £12.95. ISBN 07139-1514-5.

An international team of twenty-nine scholars from a variety of disciplines (e.g., classical studies, philosophy, archaeology, art history, sociology, and anthropology, as well as religion) contributed articles to this handy volume. Designed for students, teachers, and the general public, it is basically a dictionary of terms, but the entries are presented in a very readable form going well beyond terse definitions. Emphasis is on "living religions," with a high percentage of space devoted to religions having a large following: Islam, Buddhism, Christianity, Hinduism, and Judaism. However, ancient and lesserknown religions are also covered, as are astrology, magic, and the occult-these last "precisely because it is difficult to find reliable introductory material on them." -Introd. The classified bibliography (pp.381-446) is made up almost entirely of English-language materials and constitutes a series of good basic lists for background reading on the individual religions; references to the bibliography are provided in abbreviated form at the end of most articles. A "synoptic index" lists all articles relating to a given religion or group of religions, and an unexpected, 
but very useful, feature is a general index which leads to information on many topics not accorded a separate article in the dictionary arrangement of the text.-E.S.

\section{Shinar, Pessah. Essai de bibliographie sélec-} tive et annotée sur l'Islam maghrébin contemporain: Maroc, Algérie, Tunisie, Libye (1830-1978). Paris, Editions du Centre National de la Recherche Scientifique, 1983. 506p. 280F. LC 83-233585. ISBN 22220-2703-9.

"Islam" is considered in a broad cultural sense in this bibliography of 2,025 items (including 295 bibliographies and reference sources) on the North African Islamic countries mentioned in the subtitle. $\mathrm{Pt}$.I is basically an annotated list of source material used to compile the bibliography proper, which makes up Pt.II. The volume selectively lists works in all formats (books, articles in journals, and congress proceedings), and includes works in French, English, Arabic, Spanish, Italian, and German. Each entry includes an annotation and a list of reviews as well as the complete bibliographic information, pagination, and indication of illustrations, bibliography, maps, etc., as applicable. For books, library locations and call numbers are listed.

Each part of the bibliography is in five sections: a general section for the entire area, then a section for each country. Each section is further divided by subject, such as religious cults and edifices, law and justice, sects, ethnography and folklore, and education; these subdivisions vary from section to section. There are indexes by author, subject, cited personal name, geographical name, and by Arabic or Berber term. A useful feature is the amount of detail in the subject index where keywords or qualifiers (in the entries for "Réformisme") following an item number denote the aspect of the term treated.-J.S.

\section{LINGUISTICS}

Meier, Wilma. Bibliography of African Languages. Wiesbaden, Harrassowitz, 1984. 888p. DM140. LC 84-174201. ISBN 3447-02415-1.

Title also in German, French and Russian; introductory matter in English, Ger- man, French and Russian.

About four thousand authors from the sixteenth century through 1980 are represented in this bibliography of books and periodical articles on the whole range of African languages and dialects. In addition to works on the structure of individual languages, "the history, classification and geographical spread of linguistic phenomena, and the development of national and standard languages" (Introd.), listings for first translations of theological writings, reports of early seafarers, and language publications of missionaries and missionary societies are also included. Full bibliographical information (plus a code number indicating the language dealt with) is given in an alphabetical author section, with publications listed chronologically under each author's name. A two-part "Index of African Languages" offers first an alphabetical arrangement of the languages treated in the publications, with authors' names and abbreviated indication of their "subjects" (i.e., some twenty-five types or areas of work: semantics, teaching, lexicography, etc.). This is followed by a second alphabetical listing of the languages with a chronological listing of publication dates of relevant works together with authors' names and subject areas. Although somewhat cumbersome, these language indexes can, with a little patience, be used fairly effectively. $-E$.S.

\section{LITERATURE}

Alexander, Harriet Semmes. American and British Poetry: A Guide to Criticism, 1925-1978. Athens, Ohio, Swallow Pr., 1984. 486p. \$42. LC 83-24114. ISBN 08040-0848-5.

This is yet another guide to literary criticism, listing citations to critical writings appearing in books and magazines published from 1925 through 1978 on works of some 860 British and American poets. It is arranged alphabetically by poet, then by title of each poem. The book is well printed, easy to use, and periodical titles are not abbreviated in the entries-a boon to reference librarians.

Although the author claims to have compiled "a listing of criticism not col- 
lected elsewhere," this work duplicates much of the information in Kuntz and Martinez's Poetry Explication (Suppl. 2BD101). For example, eighteen of the thirty-one references to Matthew Arnold's "Dover Beach" in American and British Poetry are included in Poetry Explication. The period covered is nearly identical: 1925-77 for Poetry Explication and 1925-78 for American and British Poetry. Alexander covers more poems, since criticism of those of less than one thousand lines is included, whereas Kuntz and Martinez use a cutoff of five hundred lines. American and British Poetry covers more poets and more sources than Poetry Explication, though every citation in the latter is not in the former; to use the example of "Dover Beach" again, sixteen citations in Poetry Explication are not in the new book. American and British Poetry is easier to use and more complete than Poetry Explication, but the latter remains a very useful work and most libraries will not need both. - M.C.

Carpenter, Humphrey and Prichard, Mari. The Oxford Companion to Children's Literature. Oxford \& N.Y., Oxford Univ. Pr., 1984. 588p. il. \$35. LC 83-15130. ISBN 0-19-211582-0.

About twenty years ago Iona and Peter Opie, compilers of the Oxford Dictionary of Nursery Rhymes, suggested that the Press publish "a reference book dealing equally with both English and American children's books and authors, and including articles on traditional materials, illustrators, characters from cartoons, films, radio and television, and the recurrent subjects of children's reading-matter." -Pref. To that outline compilers Carpenter and Prichard added other categories of articles: "very brief summaries of the state of children's literature in all languages, countries and continents" and accounts of early school books and the educational ideas which influenced them. The resulting new "Oxford companion" reflects the growing interest in and study of children's literature.

Of the two thousand entries, nine hundred are biographical; the rest include the various genres of children's literature, characters and plot summaries of books that are deemed important, interesting, or widely known, and related aspects of children's play and learning. Asia and Africa are not as well covered as other areas. There is no bibliography, though there are occasional references in the articles to specific scholars in the field. More critical than certain other Oxford companions, this one offers an assessment of the "qualities or failings of many of the authors and books included." It should prove useful in a wide range of libraries.-E.M.

Marks, Patricia. American Literary and Drama Reviews: An Index to Late Nineteenth Century Periodicals. Boston, G. K. Hall, 1984. 344p. \$49.95. LC 82-23219. ISBN 0-8161-8470-4.

Marks, an English professor at Valdosta State College, has indexed drama and literary reviews from 1880-1900 in thirteen popular American periodicals, none of which is covered by Poole's Index to Periodical Literature. Unfortunately, only four of the titles indexed are in the microfilm collection American Periodicals, 1741-1900, so the reviews may not be readily accessible. The book is divided into two parts, the first half being a list of reviews of plays performed in New York, with a few references to productions in Boston and Philadelphia. Operas, minstrel shows, circus acts, and ballets are not covered. The plays are arranged by title; there is an author and adapter index. However, there are no cast lists. Since most of the plays performed in this period are forgotten melodramas of little literary value, this section of the bibliography will probably be of interest mainly to those studying the social history of the late nineteenth century.

The second half of the book lists previously unindexed reviews of books published or reprinted between $1880-1900$. It will be most useful to anyone wanting information on the popular press's reception of such writers as Henry James, William Dean Howells, Thomas Hardy, Mrs. Humphrey Ward, and Frank Stockton, as well as other, then popular, authors. This compilation represents a great deal of work; however, for the price, one would like more-more periodicals indexed, more years covered, and more informa- 
tion about the plays. - M.C.

\section{Middle English Prose: A Critical Guide to Ma-} jor Authors and Genres. Ed. by A. S. G. Edwards. New Brunswick, N.J., Rutgers Univ. Pr., [1984]. 452p. \$45. LC 83-2914. ISBN 0-8135-1001-5.

Similar in plan to the Modern Language Association's reviews of research, this work aims "to provide an authoritative guide to a number of important authors and genres of Middle English prose." Pref. Eighteen scholars have contributed chapters on writers such as Nicholas Love, Margery Kempe, Mandeville, and Chaucer (Malory is omitted as having recently been adequately treated elsewhere), on works such as the Ancrene Wisse, and on genres as varied as sermon literature, historical prose, medical prose, utilitarian and scientific prose, and works of religious instruction. Each chapter offers a survey of modern scholarship, suggestions for further research and notes on desiderata or lacunae, plus a bibliography of manuscripts, texts, and secondary sources. The work makes no pretense, of course, to supplanting the multi-volume Manual of the Writings in Middle English (Guide BD389), but it serves to update that work in certain areas (i.e., publications as late as 1982 are noted) and the singlevolume format makes it more nearly affordable for the individual scholar.E.S.

Smith, Eric. A Dictionary of Classical Reference in English Poetry. [Cambridge, Eng.], Boydell \& Brewer; [Totowa, N.J.], Barnes \& Noble, [1984]. 308p. $£ 29.50$. LC 83-12273. ISBN 0-389-20430-7.

This volume can serve either as a dictionary for identifying, defining, or explaining various classical names and subjects or as an aid to comparative study of classical references in English poetry. Although it is limited to classical references in the works of some eighty poets (all of them deceased, except Robert Graves), the compiler believes that the selection includes virtually all relevant poets who are commonly studied in schools and colleges or read for pleasure. The dictionary portion of the work offers a paragraph of identification or explanation of the classi- cal subject and usually concludes with an indication of its main source or sources, emphasis here being on the sources that could have been used by the English poets, not necessarily those most authoritative or reliable from a scholarly standpoint. Following the explanatory paragraph are references to the English poets and the works in which the classical subject occurs (reference is to author, title, and line numbers; excerpts from the poems are not given). An "Index of Poems, Poets and References" permits alternative approaches to the matter of the dictionary. $-E . S$.

\section{FINE ARTS}

Handbook of Latin American Art; Manual de Arte Latinoamericano: A Bibliographic Compilation. Gen. ed., Joyce Waddell Bailey. Santa Barbara, Calif., ABC-Clio, [1984]- . v.1- . (In progress) LC 8326656. ISBN 0-87436-384-5.

Contents: v.1, General references and art of the nineteenth and twentieth centuries: pt.1, North America; pt.2, South America. 2v. (1195p.) $\$ 75$ per v.

An international group of scholars has organized, compiled, and reviewed drafts of this major bibliographic undertaking in order to identify "books, articles, anthologies, exhibition catalogs, and reports (both published and unpublished) written from the nineteenth century through July of 1983 on Latin American art and artists ... in English, Spanish, Portuguese, French, German, Italian, Russian and other languages that cover ancient, colonial and contemporary art."-Pref. The work is to encompass three volumes (v.2 will cover the colonial period; v.3, the ancient period), with publication to be completed in 1985. Format is designed to be compatible with the Handbook of Latin American Studies (Guide DB157) and the overall aim is "to supplement existing bibliographies and to interfile titles from the 44 volumes of HLAS."

To accommodate bibliographic citations which cover more than one chronological period, v. 1 begins with a "General References" section (from which a few citations may be repeated in later sections if they have great relevancy therein). Following 
this general section citations are arranged geographically, subdivided by subject; each country's section ends with an alphabetical section of artists of that country. North America (including the United States, Mexico, Central America and the Caribbean) is covered in pt.1; South America (except the Guianas) in pt.2. Locations are indicated for rarely held material; serials and anthologies which have been analyzed are listed at the end of each part. Indexes for personal and corporate authors and for artists complete each volume. Unfortunately, no mention has been made of a subject index for the entire set or for each part. Despite this limitation, scholars working in Latin American studies-not necessarily those specializing in art (e.g., historians, anthropologists, psychologists, possibly even scholars in the fields of literature and ethnomusicology)-will find this a most important reference set.-E.M.

\section{CINEMA}

The International Dictionary of Films and Filmmakers. Ed. by Christopher Lyon. [Chicago], St. James Pr., [1984]v.1- . (In progress) $\$ 50$ per v. LC 8324616. ISBN 0-912289-04-X.

Contents: v.1, Films; v.2, Directors/ Filmmakers.

These first two volumes of The International Dictionary of Films and Filmmakers show this to be one of the more substantial film reference works available in English. Two more volumes are yet to appear: v. 3 will cover actors and actresses, and v.4 will be devoted to writers and production artists. When complete, the Dictionary will provide factual information, critical evaluation, and bibliographies for the films and filmmakers that are "most widely studied" and that figure prominently in "North American, British, and Western European film scholarship and criticism."-p.vii.

In both volumes the entries are written and signed by film scholars, writers, and students who are identified in a list of contributors at the end of the volume. The entries for films in v. 1 consist of original title, alternate English-language release titles, production company, technical informa- tion, release date, major production and cast credits, information on circumstances and location of filming, major awards, bibliography of primary and secondary sources, and short critical analysis; plot summary is not usually included. The entries for filmmakers include biographical information, filmography (with release dates), chronological bibliography of primary and secondary sources (including films about the directors or their work), and a short essay of critical evaluation. The extensive bibliographies, which are a particularly valuable feature, include both English- and foreign-language sources, but mention few sources published after 1980.

Although it is always possible to quibble over particular exclusions or inclusions in a work of this type, the editors and advisory board have done well in covering many of the films and most of the directors about whom students and others will frequently seek information. The most serious flaws include occasional unevenness in treatment (Does "The Wild Bunch" really merit $31 / 2$ pages, substantially more than almost any other film?), several incomplete entries (e.g., entries for Jan Kadar, Marcel Ophuls, and "The River" [1937] lack critical evaluations), gaps in some of the bibliographies (e.g., the bibliography for Vera Chytilová cites primarily Czech sources while omitting some of the more accessible French and English ones), and numerous "typos." One hopes that these matters will be corrected in future editions of this useful work.-A.L.

\section{FOLKLORE}

Clements, William M. and Malpezzi, Frances M. Native American Folklore, 1879-1979: An Annotated Bibliography. Athens, Ohio, Swallow Pr., 1984. 247p. \$34.95. LC 83-6672. ISBN 0-8040-0831-0. The compilers of this attractively produced bibliography, both with the English Department of Arkansas State University, have "attempted a thorough coverage of books and articles in English" written on American Indian folklore from 1879, when the Bureau of Ethnology of the Smithsonian Institution was established, through 1979; selected pre-1879 items have also 
been included. Newspaper articles, reviews, and children's books have been excluded. Folklore is defined broadly as the "texts and performances of verbal art," covering "oral narratives, songs, chants, prayers, formulas, orations, proverbs, riddles, word play, music, dances, games and ceremonies." -Introd. The entries cover "all Native Americans who have traditionally resided north of Mexico."

The work is organized by tribal groups and within the groups by cultural areas, based on the divisions in G. P. Murdock's Ethnographic Bibliography of North America. There is an author, editor and translator index, as well as a subject index. All of the nearly 5,500 entries have brief descriptive, and in some cases evaluative, annotations. This bibliography is thorough, informative, and easy to use.-M.C.

\section{BLACK STUDIES}

Newman, Richard. Black Access: A Bibliography of Afro-American Bibliographies. Westport, Conn., Greenwood Pr., 1984. 249p. \$35. LC 83-8537. ISBN 0313-23282-2.

Over three thousand citations to bibliographies on Afro-American subjects with publication dates ranging from 1905 to the early 1980 s make up this important new work. Arranged alphabetically by author, the citations are not annotated, but comprehensiveness is suggested by the inclusion of the number of pages for each entry. To qualify for inclusion a bibliography had to be "separately published" (i.e., as a book, pamphlet, article, or chapter), thereby excluding appendices to monographs. Included are bibliographic essays, guides to various source materials such as checklists of manuscripts, archives, etc., and material on historiography and AfroAmerican libraries and book-collecting. Works on the Civil War excepted, coverage extends to "every bibliography on black subjects as well as bibliographies on some non-black persons whose life and work has been significant in AfroAmerican history" (Pref.); slavery and Reconstruction are included. "Fifty Years of Collecting," an essay by Dorothy Porter, librarian emerita at Howard University, serves as an introduction; chronological and subject indexes complete the volume. Black Access is recommended for all libraries with Afro-American collections. - L.S.

\section{POLITICAL SCIENCE}

DeGregorio, William A. The Complete Book of U.S. Presidents. N.Y., Dembner Books, 1984. 691p. \$22.50. LC 83-23201. ISBN 0-9348-7836-6.

Not only the essential facts of each individual's tenure, but "many other related illuminating and surprising bits of historical information" (Pref.) are presented in this new compilation on the U.S. presidents. The author has drawn upon existing biographical works as well as questionnaire results obtained from many presidential descendants to produce an assortment of personal details, opinions, and other interesting information not included in Joseph Kane's Facts About the Presidents (4th ed. 1981). Articles are divided into major headings and subheadings that extend beyond the basic areas of campaigns and issues, election results, and major administrative accomplishments into those such as military service, career before the presidency, inaugural address, education, religion, and recreation. The Watergate scandal, presidential assassinations, and other important events receive lengthy treatment, and individual biographical sketches of the vicepresidents and presidents' family members are included.

Some detail is lacking, such as a breakdown by state of electoral votes won by each president, and there is no section of comparative data like that found in Kane's work. However, a great many peripheral but significant facts are presented. Cabinet members each receive brief career summaries, as do Supreme Court justices, and there are numerous details of the presidents' personal lives. Notes and a bibliography appear at the end of each article, along with quotations both by and about the presidents. The volume includes an index.

While enjoyable to read, the narrative is not without bias. The facts of the presidencies, particularly those of a personal and familial nature, are often presented in 
order to convey a particular impression. These are days of knocking down the protective walls that surround public figures; perhaps this is one reference work that helps to serve that purpose, while providing useful and relatively obscure data in the process. $-D . H$.

\section{The Nuclear Almanac: Confronting the Atom} in War and Peace. Comp. and ed. by faculty members at the Massachusetts Institute of Technology. Ed. by Jack Dennis. Reading, Mass., Addison-Wesley, 1984. 546p. \$35. LC 82-20596. ISBN 02010-5331-4.

With the "proliferation" of guides, handbooks, dictionaries and bibliographies on the issue of nuclear energy and all of the hazards that accompany the nuclear age, The Nuclear Almanac stands out as an excellent starting point for a "factual account of the discovery, development and use of nuclear energy, and a critical evaluation of policy issues raised by nuclear armaments and nuclear power." $-p . v$.

The signed essays, contributed by MIT faculty, are grouped under major headings: the history of nuclear weapons; the effects of nuclear weapons; atomic warfare, its technologies and its consequences; international issues, including arms control negotiations; the nonmilitary uses and abuses of nuclear energy; public response; and scientific background. There is some overlap in information, and the order of presentation could have been improved, but these are minor criticisms. The work in general is concise and well written. Each essay is replete with photographs, chronologies, tables, documentary excerpts and other useful inserts, as well as a short "suggested readings" list. A detailed index directs the reader to specific information; however, one of the most appealing features of the almanac is the fact that it encourages the type of browsing that truly educates. The MIT Faculty Coalition for Disarmament hopes that as a result of making this information more readily accessible, public opinion will be better informed and public policy will be more responsible. The Nuclear Almanac should serve this purpose very well.-L.B.

\section{GEOGRAPHY}

Canby, Courtlandt. The Encyclopedia of Historic Places. N.Y., Facts On File, [1984]. 2v. (1053p.) il., maps. \$120. LC 80-25121. ISBN 0-871-96126-1.

This work is intended to be a "comprehensive encyclopedia or dictionary" which provides "detailed coverage on all geographic locations of historical significance-towns, cities, countries, provinces, regions, empires, deserts, forts, battle sites, lakes, mountains, rivers, shrines, and archaeological sites ... . from the remains of human beginnings to the present."-Pref. Each entry consists of: the most common English name of the place, followed in brackets by variant spellings, native name or spellings, and ancient or former names; the modern geographical location; and important events in its history, its historical significance, or a précis of its history. No pronunciations are given; the Wade-Giles system of transliteration of Chinese names is used. There is an extensive system of cross references to variant name forms and related entries. The volumes are handsomely printed and bound.

While Canby implies that the coverage of his encyclopedia is more detailed than that of the "standard short-entry alphabetical reference books" (he cites Webster's New Geographical Dictionary, the ColumbiaLippincott Gazetteer of the World, and the New Columbia Encyclopedia), the majority of his entries are also brief and are sometimes longer only because a completesentence form is used. Some entries bear an uncanny resemblance to those in the "standard" books, although no bibliographic references or list of sources are given. Captions for the numerous illustrations often read like tourist guidebook copy.

In collections already owning standard geographical dictionaries, this work will be used primarily to identify alternate forms of names, or names of forts, battle sites, archaeological sites, shrines, and ancient places. It is an expensive title necessary only for the most comprehensive collection, or a collection lacking the older, standard titles.-D.G. 


\section{HISTORY \& AREA STUDIES}

Gurock, Jeffrey S. American Jewish History: A Bibliographical Guide. N.Y., AntiDefamation League of B'nai B'rith, 1983. 195p. \$6.95 pa. LC 83-71207. ISBN 0-88464-037-X.

Gurock has managed to include a great deal of information in this small, yet compact volume. One of a series of bibliographies commissioned by the AntiDefamation League, the volume provides a new look at American Jewish history with a particular emphasis on the work produced during the last quarter-century. Employing the form of evaluative bibliographical essays, the compiler attempts to identify "the most useful volumes extant for studying and exploring the major issues" in the field. The work is in six major sections ("Introductory and Reference Works," "Colonial and Early National Period," "The Era of German Migration," "The Era of East European Migration,"

"From the Close of East European Immigration to the Present," and "Special Topics"), all but the first preceded by a brief introduction. Basic works are examined first in each section, followed by treatment of specific themes within the general heading. There is also a section on "Suggestions for Further Research." The complete bibliography of works cited (approximately 850 books and articles published prior to Sept. 1, 1982), and author and title indexes complete the volume. It is recommended for all collections of immigrant and ethnic materials.-L.S.

Kodansha Encyclopedia of Japan. Tokyo, Kodansha Ltd., 1983. 9v. il. \$550. LC 8380778. ISBN 0-8701-1620-7.

This is the first substantial encyclopedia on Japan to be published in a Western language. Unlike earlier, small Westernlanguage encyclopedias devoted to Japan which were compiled and edited by a single author, this is the product of an impressive cooperative project directed by a joint advisory board in Tokyo and Cambridge, Mass. Articles were written by 680 Japanese and 524 non-Japanese scholars from twenty-seven nations, and the editors have been successful in providing authoritative information for lay- men as well as for the specialist. All entries are signed with full name of the contributor and accompanied by useful bibliographies.

Most articles are of short or medium length, but substantial articles are offered on major topics such as Japanese history, literature, and political parties. General topics are dealt with only in relation to Japan (e.g., "psychology" in an article on "Psychology in Japan"). Biographical notices cover both historical and contemporary persons, and non-Japanese figures such as Generals Kuropatkin and MacArthur are included for their roles in Japanese history. An article entitled "Lenin and Japan" discusses his influence in Japan, although no biography of Lenin is given. Besides personal and geographical names, the encyclopedia contains a number of profiles of business corporations. It also generously provides explanations of legal concepts and legislation, particularly in relation to commercial laws. Considerable emphasis is placed on legal, economic, and political aspects of Japanese affairs; arts and letters, however, are not neglected. Although there are no color plates, a judicious use of line drawings and monochrome photographs helps to convey information effectively. Japanese characters are not used in the main body of the work, but the detailed index (v.9 of the set) gives most terms in Japanese as well as roman characters. $-J$.S.

Schultz, Arthur. German-American Relations and German Culture in America: A Subject Bibliography, 1941-1980. Millwood, N.Y., Kraus Internat. Pubns., [1984]. 2v. (1279p.) \$210. LC 8248987. ISBN 0-527-71572-7.

Pochmann and Schultz's 1953 Bibliography of German Culture in America to 1940 (Guide DB25) was reissued in 1982 in a new edition corrected and expanded by Schultz, who has now continued that bibliography with the present work which lists publications and reprints of the 1941-80 period. This extension aims "to provide a comprehensive and often annotated guide to works on German ethnic culture and history in America, as well as sources dealing with German-American literary, philosophical, and cultural rela- 
tions. . . . It seeks out those influences that came from Europe to America and deals with the ideas, population movements, and cultural features that moved westward across the Atlantic from Europe."-Pref. To this end the compiler has organized books, monographs, articles, dissertations, and appropriate manuscript collections and other unpublished materials within a topical framework.

The varied topics of coverage begin with a general section (which includes popular culture, archives, opinions and views), moves to ethnic subgroups, then on to sections for various types of influencesliterary, philosophical, educational, linguistic, folkloric, as well as trade and diplomatic relations. There are sections for local history, for biographies of noted German-Americans, and family genealogies. An annotation may consist of a comment or a list of reviews. The index includes authors, reviewers, titles, institutions, geographical names, and subjects, but not the genealogies (which are excluded because already alphabetically arranged). A useful appendix lists academic programs and symposia, festivals and celebrations, historic sites, library collections and archives, museums and exhibitions, giving for each an address and a sentence or two of description. The bibliography is exceptionally thorough and will be valuable for in-depth research in many fields. - E.M.

\section{PSYCHOLOGY}

Osier, Donald V. and Wozniak, Robert $\mathrm{H}$. A Century of Serial Publications in Psychology, 1850-1950: An International Bibliography. Millwood, N.Y., Kraus International Pubns., [1984]. 805p. \$90. LC 82-48989. ISBN 0-527-98196-6.

Although unnumbered in the series statement within the volume, spine marking identifies this as no. 2 in the series "Bibliographies in the History of Psychology and Psychiatry." And it is clearly a contribution to the history of the field: arrangement is chronological by inaugural year of a serial's publication; there is careful attention to details of publishing history (including changes of title, sponsoring bodies, dates of publication, suspensions, and principal editors with dates of service); and 1950 is a firm cutoff date-i.e., there is no data past 1950 on continuing publications-a decision dictated by the compilers' desire to focus on historical material. Moreover, while the period of coverage is designated as $1850-1950$, a number of pre-1850 (i.e., 1783-1849) publications are included "to provide historical context for the body of the work" (Introd.), and Wozniak's "A Brief History of Serial Publications in Psychology" (pp.xvii-xxxiii) is an informative background essay. Some 1,107 serials are fully treated in the chronological main entry listing, and an appendix of titles "not primarily psychological but which contain material relevant to psychology or written by psychologists" lists another 739 serials (with dates of publication) grouped in eleven subject categories. Analytics for monographic series are an unexpected bonus. There are separate title and name indexes.-E.S.

Vande Kemp, Hendrika. Psychology and Theology in Western Thought, 1672-1965; A Historical and Annotated Bibliography. Millwood, N.Y., Kraus Internat. Pubns., [1984]. 367p. (Bibliographies in the history of psychology and psychiatry) \$65. LC 82-49045. ISBN 0-52792779-1.

Since the late 1960 s great interest has been shown in integrating the fields of psychology and theology, as evidenced by the appearance of five specialized journals, many training institutions, and a growing list of relevant publications from Christian and Jewish publishing houses. This bibliography addresses the movement leading toward "psychotheological integration" - which explains the dates of coverage (1672-1965). Focus is on booklength publications, monographs, pamphlets, and journal titles; for periodical articles the compiler refers the user to the bibliographies on psychology and religion by Beit-Hallahmi (Suppl. 2BB1), Capp (Suppl. BB3), and Meissner (noted in Suppl. BB3).

The entries are arranged by topics, then chronologically by date of publication. Topics range from "Historical and philosophical bases for integration" to "Theo- 
logical perspectives on personality theory and psychology," and from "Psychiatric and psychoanalytic perspectives" to "The professionalization of psychotheology." Considerable attention is given to the particular "schools" or traditions, and the annotations reflect this interest. A final section treats the major journals, institutions, and special book series. The volume is well indexed, with separate name, institution, title and subject indexes.-E.M.

\section{NEW EDITIONS, SUPPLEMENTS, ETC.}

Information on libraries, publishers, and the book trade in thirty-one African nations is included in the third edition of The African Book World \& Press; A Directory, edited by Hans M. Zell and Carol Bundy (München \& N.Y., H. Zell/K. G. Saur, 1983. 285p. \$85). It follows the plan of the previous editions (see Suppl. AA100), but is considerably expanded, offering information on about 4,600 institutions, agencies, and organizations.

Now arranged on an English rather than a German base, the third edition of Imre Mora's Publisher's Practical Dictionary in 20 Languages (München \& N.Y., K. G. Saur, 1984. 417p. \$65) lists more than a thousand terms, with emphasis on "words that are relevant-i.e., actually used-in the publisher/publisher or author/publisher connection." -Editor's Note. It employs the tabular arrangement of the earlier edition (1974, Suppl. AA57; repr. 1977 as "'2d ed."), with indexes from the other nineteen languages.

About seven thousand titles are added in Periodicals from Africa: A Bibliography and Union List of Periodicals in Africa; First Supplement, compiled and edited by David Blake and Carole Travis (Boston, G. K. Hall, 1984. 217p. \$60). Sponsored by the Standing Conference on Library Materials on Africa, it follows the plan of the main volume (1977; Suppl. AE37) and concerns itself with the holdings of British libraries. The end of 1979 is the cutoff date. "Europe: East and Southeast; USSR" is the title of v.3 of Historical Periodicals Directory (Santa Barbara, Calif., ABC-Clio, 1984. 252 p. \$89). It offers 1,555 entries for relevant periodicals in some fifteen lan- guages, arranged on a country basis, then alphabetically by main entry.

Hispanic American Periodicals Index, 1970-1974, edited by Barbara G. Valk (Los Angeles, UCLA Latin American Center Pubns., Univ. of Calif., Los Angeles, 1984. $3 v . \$ 600)$, offers retrospective indexing of some 229 journals, bridging the gap between the cessation of the Index to Latin American Periodicals (Guide AE213) and the annual volumes of $H A P I$ which begin with 1975 (see Suppl. AE55). Volumes 1-2 offer a subject approach to the indexed material; v. 3 is an author index. Students and others who read only English will find that a newly-published "spinoff" from HAPI will simplify their search for Englishlanguage materials: Hispanic American Periodicals Index: Articles in English, 1976-1980 (Westwood, Mass., Faxon, 1984. 403p. \$75) offers a five-year cumulation of the English-language citations from the annual volumes. The volume could prove particularly useful in undergraduate library collections which do not include the full set of HAPI.

Who's Who in Frontier Science and Technology (1st ed., 1984/85. Chicago, Marquis, $1984.846 \mathrm{p} . \$ 84.50$ ) is the latest addition to the long list of "who's whos" published by Marquis. It offers biographical sketches of about 16,500 "scientists and technologists who are currently working in North America in the frontier areas of their respective specialties."-Pref. Following the alphabetically-arranged biographical sketches is an index of "Fields and Subspecialties" -some 360 specialties (such as Ecosystems analysis, High energy astrophysics, Remote sensing, Population biology, Bioinstrumentation, Prosthodontics, Geothermal power) grouped within twenty-four major fields.

About three hundred new titles have been added in the second edition of Margaret C. Patterson's Literary Research Guide (N.Y., Modern Language Assoc. of America, 1983. 559p. \$25), and there has been some pruning of superseded works. As a guide for the student and independent research worker, "the primary concern ... . is the content of the best reference books in literature and the way in which that content can help literature students produce scholarly research." -Pref. In addi- 
tion to updating the chapters of the 1976 Anglo-Irish Literature: A Review of Research (Suppl. BD120), Richard J. Finneran's Recent Research on Anglo-Irish Writers (N.Y., Modern Language Assoc. of America, 1983. 361p. \$25) adds new chapters on modern fiction and poetry. With the exception of the George Moore section (which ends with 1979), bibliographies are updated through 1980, with some 1981 listings.

W. H. Chaloner's and R. C. Richardson's Bibliography of British Economic and Social History (Manchester, Eng., \& Dover, N.H., Manchester Univ. Pr., 1984. 208p. $\$ 37.50$ ) represents a revised and enlarged edition of the same compilers' British Economic and Social History (1976; Suppl. CC14). It contains about 5,800 selected entries as compared with 4,200 in the earlier work. A companion volume covering continental Europe, compiled by Derek $\mathrm{H}$. Aldcroft and Richard Rodger, has been published as Bibliography of European Economic and Social History (Manchester, Eng., \& Dover, N.H., Manchester Univ. Pr., 1984. 243p. \$37.50). "The bibliography covers writings on the period 1700 to 1939 and includes most of the literature published during the twentieth century and a small selection of the important, and still relevant, writings which appeared in the nineteenth century." - Pref. Both volumes follow a classed arrangement with author index; each has a detailed table of contents, but no alphabetical subject index.

Part I of Chauncy D. Harris's Bibliography of Geography, published 1976 (Suppl. CL7), was an introduction to general aids in the field. After an unforeseen delay, the first volume of Part II of the "Regional" section of the bibliography has now appeared (Chicago, Univ. of Chicago, Dept. of Geography, 1984. 178p. Research paper no.206. \$8). Devoted to the United States, it lists more than 1,200 items on "physical geography and related earth science and environmental fields; human geography and related social sciences; and the regions, states, and cities of the United States."-Pref. Emphasis is on works published in the last fifteen years; most entries are annotated.

Latin American Politics: A Historical Bibliography (Santa Barbara, Calif., ABC-Clio,
1984. 290p. $\$ 60.50$ ) is no. 16 in the "Clio Bibliography Series." Like other volumes in that series it provides bibliographic citations and abstracts drawn from the history database of the ABC-Clio Information Services. It follows a topical arrangement, with separate author and subject indexes.

Rhode Island; A Bibliography of Its History (Hanover, N.H., University Pr. of New England, 1983. 229p. \$30) forms volume five of the "Bibliographies of New England History" series prepared for the Committee for a New England Bibliography. Edited by Roger Parks and following the plan and guidelines of the earlier volumes (see Suppl. DB32, 2DB20), it lists more than 4,100 "published writingsbooks, pamphlets, magazine and journal articles-about the history of Rhode Island, its cities, towns, and counties, its people and their institutions."-Introd.

George D. Selim's American Doctoral Dissertations on the Arab World: Supplement, 1975-1981 (Wash., Lib. of Congress, Near East Section, African and Middle Eastern Div., 1983. 200p. \$9) lists 1,296 dissertations from United States and Canadian universities. Like the parent work ( $2 \mathrm{~d}$ ed. 1976; Suppl. DE17), it is an author listing with subject index.

"Fossil Fuels" is the title of v.3 of R. David Weber's Energy Information Guide (Santa Barbara, Calif., ABC-Clio, 1984. $\$ 44.50)$, the earlier volumes having dealt with "General and Alternative Energy Sources" and "Nuclear and Electric Power." It offers annotated entries for a wide range of relevant reference works such as dictionaries, handbooks, documentary and statistical sources, directories, indexes, abstracting services, and databases. The volume is paged continuously with v.1-2 (for a total of 1,357 pages) and includes cumulative author, title, and subject indexes for the full set.

Having previously complained in this column of the inconvenience resulting from a seeming trend toward publishing various "heavy use" reference works in two volumes rather than one, it seems only fair to commend the return of The World of Learning (Ed. 34, 1983/84) to the single-volume format. May the publisher of Ulrich's please take note!-E.S. 


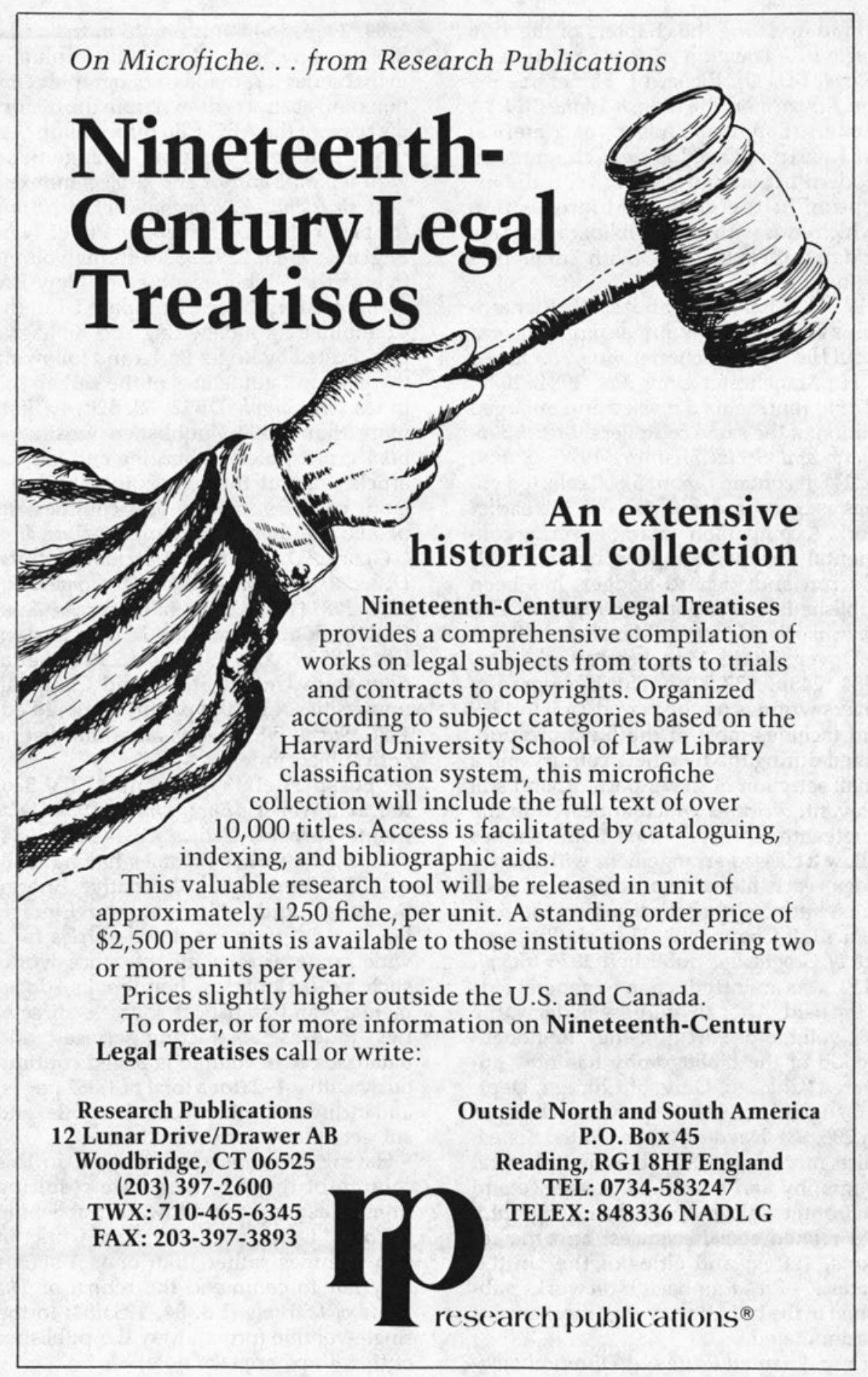

